\title{
Etiology, Risk Factors and Sex Differences in Ischemic Stroke in the Ludwigshafen Stroke Study, a Population-Based Stroke Registry
}

\author{
F. Palm $^{\mathrm{a}} \quad$ C. Urbanek ${ }^{\mathrm{a}} \quad$ J. Wolf ${ }^{\mathrm{a}} \quad$ F. Buggle ${ }^{\mathrm{a}} \quad$ T. Kleemann $^{\mathrm{b}} \quad$ M.G. Hennerici ${ }^{\mathrm{d}}$ \\ G. Inselmann ${ }^{c}$ M. Hagar ${ }^{a} \quad$ A. Safer ${ }^{\mathrm{e}}$ H. Becher A.J. Grau $^{\mathrm{a}}$ \\ Departments of a Neurology and ${ }^{b}$ Cardiology, Klinikum Ludwigshafen, and ${ }^{\mathrm{c} D e p a r t m e n t}$ of Internal Medicine, \\ Marienkrankenhaus, Ludwigshafen, ${ }^{d}$ Department of Neurology, University of Heidelberg, Universitätsklinikum \\ Mannheim, Mannheim, and ${ }^{\mathrm{e}}$ Institute of Public Health, University of Heidelberg, Heidelberg, Germany
}

\section{Key Words}

Population-based stroke registry $\cdot$ Ischemic stroke •

Stroke etiology $\cdot$ Gender $\cdot$ Stroke mortality

\begin{abstract}
Background: Stroke etiology in ischemic stroke guides preventive measures and etiological stroke subgroups may show considerable differences between both sexes. In a population-based stroke registry we analyzed etiological subgroups of ischemic stroke and calculated sex-specific incidence and mortality rates. Methods: The Ludwigshafen Stroke Study is a prospective ongoing population-based stroke registry. Multiple overlapping methods of case ascertainment were used to identify all patients with incident stroke or transient ischemic attack. Modified TOAST (Trial of Org 10172 in Acute Stroke Treatment) criteria were applied for subgroup analysis in ischemic stroke. Results: Out of 626 patients with first-ever ischemic stroke in 2006 and 2007, women $(\mathrm{n}=327)$ were older $(73.5 \pm 12.6$ years $)$ than men $(n=299 ; 69.7 \pm 11.5$ years; $p<0.001)$. The age-adjusted incidence rate of ischemic stroke was significantly higher in men $(1.37 ; 95 \% \mathrm{Cl} 1.20-1.56)$ than in women $(1.12 ; 95 \% \mathrm{Cl}$ $0.97-1.29 ; p=0.04)$. Cardioembolism $(n=219 ; 35.0 \%)$, smallartery occlusion $(n=164 ; 26.2 \%)$, large-artery atherosclero-
\end{abstract}

sis $(\mathrm{n}=98 ; 15.7 \%)$ and 'probable atherothrombotic stroke' ( $n=84 ; 13.4 \%$ ) were common subgroups of ischemic stroke. Stroke due to large-artery atherosclerosis $(p=0.025)$, current smoking $(p=0.008)$, history of smoking $(p<0.001)$, coronary artery disease $(p=0.0015)$ and peripheral artery disease $(p=$ 0.024 ) was significantly more common in men than in women. Overall, 1-year survival was not different between both sexes; however, a significant age-sex interaction with higher mortality in elderly women ( $>85$ years) was detected. Conclusions: Cardioembolism is the main source for ischemic stroke in our population. Etiology of ischemic stroke differs between sexes, with large-artery atherosclerotic stroke and associated diseases (coronary artery disease and peripheral artery disease) being more common in men.

Copyright $\odot 2011$ S. Karger AG, Basel

\section{Introduction}

Stroke, especially ischemic stroke, is a multifactorial disease and its various etiologies require different preventive strategies. Analyzing etiological stroke subgroups may help to explain regional differences in stroke incidence and also to reduce the burden of stroke in the future. Recently published data on stroke incidence in the

\section{KARGER}

Fax +41613061234 E-Mail karger@karger.ch www.karger.com

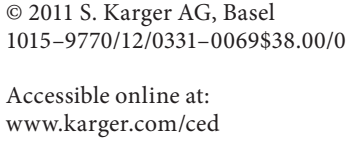

Dr. Frederick Palm

Department of Neurology, Städtisches Klinikum Ludwigshafen

Bremserstrasse 79

DE-67063 Ludwigshafen a. Rh. (Germany)

Tel. +49621503 4232, E-Mail palmf@klilu.de 
Ludwigshafen Stroke Study (LuSSt) showed slightly higher stroke incidence rates especially of ischemic stroke in all age groups combined and relatively high incidence rates in middle-aged patients (45-64 years) compared to other registries in Western and Central Europe [1]. A recent systematic review summarized significant sex-specific differences in the incidence of stroke and its etiological subtypes [2]. As variations in stroke etiology may call for different diagnostic, therapeutic and preventive strategies we analyzed etiology and sex-specific differences in ischemic stroke.

We report here on analyses drawn from the LuSSt based on data from 2006 and 2007.

\section{Subjects and Methods}

Having started on January 1, 2006, the LuSSt is a prospective population-based stroke registry in the population of the city of Ludwigshafen am Rhein recording all strokes and transient ischemic attacks in patients of all age groups. A detailed description of LuSSt has recently been published [1]

Executive Summary of Study Population, Case Ascertainment and Standard Definitions

Ludwigshafen is an industrial city in the Federal State of Rhineland-Palatinate in the west of Germany. As of December 31, 2006 the total source population was 167,906 inhabitants $(83,017$ males and 84,889 females). The patients' postal address accounted for affiliation to the study population. Multiple overlapping methods of patient identification were used in order to achieve complete case ascertainment as described before [1]. Nonhospitalized patients were examined by a professional member of the study team if they gave informed consent. If they refused such an examination, data were obtained from the attending physician. The study was approved by the ethics committee of the Landesärztekammer Rhineland-Palatinate and by the data protection commissioner of Rhineland-Palatinate.

Stroke was defined according to the definition of the World Health Organization [3]. Stroke subtype classification was based on the results of brain imaging, discriminating between ischemic stroke, intracerebral hemorrhage or subarachnoid hemorrhage. If no brain imaging was available, the stroke type was defined as undetermined.

\section{Etiology of Ischemic Stroke}

Between January 1, 2006 and December 31, 2007, 725 patients (375 women, 350 men) with first-ever stroke including 626 patients (327 women, 299 men) with first-ever ischemic stroke (FEIS) were identified among the study population. We used a modification of the TOAST (Trial of Org 10172 in Acute Stroke Treatment) criteria to define etiological subtypes of ischemic stroke. Stroke due to large-artery atherosclerosis, cardioembolism, small-artery occlusion, stroke of other determined cause and stroke of undetermined etiology (except from two or more competing etiologies) were diagnosed according to the TOAST criteria [4]. In addition, we diagnosed 'probable atherothrombot- ic stroke' in patients with stenoses $<50 \%$ diameter reduction on Duplex sonography or CT, MR or digital subtraction angiography and brain infarctions $>1.5 \mathrm{~cm}$ in the absence of any source of cardioembolism. This category is comparable to 'atherosclerosis without stenosis' in the Lausanne Stroke Registry and 'likely atherothrombotic stroke' in the PERFORM study $[5,6]$. In patients with more than one potential cause for stroke, etiology was assigned to the most likely causative mechanism according to the SSS-TOAST classification [7]. Classification was performed by experienced neurologists of the study team and controversial diagnoses were discussed and agreed in study meetings. Interrater agreement in the use of modified TOAST criteria was analyzed by comparing the classification of 100 randomly selected patients by two different raters.

\section{Stroke Risk Factors}

Cardiovascular risk factors were defined according to current national and international guidelines $[8,9]$. Hypertension was diagnosed if the patient was on antihypertensive medication on admission, if hypertension had been diagnosed before by a physician or if blood pressure was $>140 / 90 \mathrm{~mm} \mathrm{Hg}$ in 2 or more measurements $>3$ days after stroke. Diabetes mellitus was acknowledged in patients with fasting blood glucose level above $125 \mathrm{mg} / \mathrm{dl}$, with antidiabetics on admission or if this diagnosis had previously been made by a physician. Atrial fibrillation (AF) was diagnosed if the patient had a history of AF or if permanent or intermittent AF was present on ECG or Holter monitoring. Patients with fasting cholesterol levels $>200 \mathrm{mg} / \mathrm{dl}$ or LDL cholesterol $>140 \mathrm{mg} / \mathrm{dl}$ or patients who were on cholesterol-lowering medication on admission were diagnosed as having hypercholesterolemia. Current smoking was defined as current daily tobacco use (at least one cigarette, cigar or pipe). Patients with a history of tobacco use of 6 months or more were classified as having a history of smoking. Coronary artery disease (CAD) was diagnosed in patients with a history of myocardial infarction, coronary stenting or coronary artery bypass surgery or a history of angina pectoris. Patients with a past diagnosis of peripheral artery disease (PAD) or with a history of stenting or bypass surgery in the arteries of the lower limbs or with a typical history of intermittent claudication of vascular origin were diagnosed as suffering from PAD.

\section{Statistical Analyses}

We calculated sex-specific, crude and age-adjusted incidence rates per 1,000 person-years for all cases of etiological subtypes in ischemic stroke [10-12]. Population numbers at study midpoint (December 31, 2006) multiplied by 2 were used as person-year approximation. The standard European population was used for standardization [13]. Exact 95\% confidence intervals for the rates based on the Poisson distribution were calculated. Difference in age distribution was evaluated using a two-sided $t$ test. The $\chi^{2}$ test was used to analyze sex differences in stroke risk factors and stroke etiology. Kaplan-Meier curves for sex-specific survival are provided. Gender differences in 1-year survival were analyzed using Cox regression analysis with the factors age, gender and age by gender. The effect of age was either analyzed with age as a continuous variable or using age categories. Interrater agreement in the use of modified stroke criteria was analyzed by Cohen's к соefficient. Data were analyzed using SAS 9.1.3 software. 
Table 1. Incidence rates (IR) per 1,000 person-years by stroke etiology in ischemic stroke according to sex

\begin{tabular}{|c|c|c|c|c|c|c|c|c|c|c|c|}
\hline \multirow[t]{2}{*}{ Stroke etiology } & \multicolumn{3}{|l|}{ Total } & \multicolumn{3}{|l|}{ Men } & \multicolumn{3}{|c|}{ Women } & \multicolumn{2}{|c|}{$p$ value, $\chi^{2}$ test } \\
\hline & $\begin{array}{l}\text { cases } \\
(\%)\end{array}$ & IR (95\% CI) & $\begin{array}{l}\mathrm{IR}^{\mathrm{a}} \\
(95 \% \mathrm{CI})\end{array}$ & $\begin{array}{l}\text { cases } \\
(\%)\end{array}$ & $\begin{array}{l}\text { IR } \\
(95 \% \mathrm{CI})\end{array}$ & $\begin{array}{l}\mathrm{IR}^{\mathrm{a}} \\
(95 \% \mathrm{CI})\end{array}$ & $\begin{array}{l}\text { cases } \\
(\%)\end{array}$ & $\begin{array}{l}\text { IR } \\
(95 \% \mathrm{CI})\end{array}$ & $\begin{array}{l}\mathrm{IR}^{\mathrm{a}} \\
(95 \% \mathrm{CI})\end{array}$ & IR & $\mathrm{IR}^{\mathrm{a}}$ \\
\hline $\begin{array}{l}\text { Large-artery } \\
\text { atherosclerosis }\end{array}$ & $\begin{array}{l}98 \\
(15.7)\end{array}$ & $\begin{array}{l}0.29 \\
(0.24-0.36)\end{array}$ & $\begin{array}{l}0.20 \\
(0.15-0.25)\end{array}$ & $\begin{array}{l}57 \\
(19.1)\end{array}$ & $\begin{array}{l}0.34 \\
(0.26-0.44)\end{array}$ & $\begin{array}{l}0.26 \\
(0.19-0.35)\end{array}$ & $\begin{array}{l}41 \\
(12.5)\end{array}$ & $\begin{array}{l}0.24 \\
(0.17-0.33)\end{array}$ & $\begin{array}{l}0.15 \\
(0.1-0.22)\end{array}$ & 0.025 & 0.023 \\
\hline $\begin{array}{l}\text { Probable athero- } \\
\text { thrombotic stroke }\end{array}$ & $\begin{array}{l}84 \\
(13.4)\end{array}$ & $\begin{array}{l}0.25 \\
(0.2-0.31)\end{array}$ & $\begin{array}{l}0.17 \\
(0.13-0.22)\end{array}$ & $\begin{array}{l}35 \\
(11.7)\end{array}$ & $\begin{array}{l}0.21 \\
(0.15-0.29)\end{array}$ & $\begin{array}{l}0.17 \\
(0.11-0.24)\end{array}$ & $\begin{array}{l}49 \\
(15)\end{array}$ & $\begin{array}{l}0.29 \\
(0.21-0.38)\end{array}$ & $\begin{array}{l}0.18 \\
(0.12-0.25)\end{array}$ & 0.229 & 0.859 \\
\hline Cardioembolism & $\begin{array}{l}219 \\
(35)\end{array}$ & $\begin{array}{l}0.65 \\
(0.57-0.74)\end{array}$ & $\begin{array}{l}0.40 \\
(0.33-0.47)\end{array}$ & $\begin{array}{l}106 \\
(35.5)\end{array}$ & $\begin{array}{l}0.64 \\
(0.52-0.77)\end{array}$ & $\begin{array}{l}0.48 \\
(0.38-0.59)\end{array}$ & $\begin{array}{l}113 \\
(34.6)\end{array}$ & $\begin{array}{l}0.67 \\
(0.55-0.8)\end{array}$ & $\begin{array}{l}0.32 \\
(0.24-0.41)\end{array}$ & 0.815 & 0.022 \\
\hline $\begin{array}{l}\text { Small-artery } \\
\text { occlusion }\end{array}$ & $\begin{array}{l}164 \\
(26.2) \\
\end{array}$ & $\begin{array}{l}0.49 \\
(0.42-0.57)\end{array}$ & $\begin{array}{l}0.35 \\
(0.29-0.42) \\
\end{array}$ & $\begin{array}{l}77 \\
(25.8) \\
\end{array}$ & $\begin{array}{l}0.46 \\
(0.37-0.58)\end{array}$ & $\begin{array}{l}0.37 \\
(0.28-0.47)\end{array}$ & $\begin{array}{l}87 \\
(26.6) \\
\end{array}$ & $\begin{array}{l}0.51 \\
(0.41-0.63) \\
\end{array}$ & $\begin{array}{l}0.32 \\
(0.24-0.41)\end{array}$ & 0.808 & 0.440 \\
\hline $\begin{array}{l}\text { Stroke of unde- } \\
\text { termined etiology }\end{array}$ & $\begin{array}{l}55 \\
(8.8)\end{array}$ & $\begin{array}{l}0.16 \\
(0.12-0.21)\end{array}$ & $\begin{array}{l}0.10 \\
(0.07-0.14)\end{array}$ & $\begin{array}{l}21 \\
(7)\end{array}$ & $\begin{array}{l}0.13 \\
(0.08-0.19)\end{array}$ & $\begin{array}{l}0.07 \\
(0.03-0.12)\end{array}$ & $\begin{array}{l}34 \\
(10.4) \\
\end{array}$ & $\begin{array}{l}0.20 \\
(0.14-0.28) \\
\end{array}$ & $\begin{array}{l}0.13 \\
(0.08-0.2)\end{array}$ & 0.136 & 0.064 \\
\hline $\begin{array}{l}\text { Stroke of other } \\
\text { determined causes }\end{array}$ & $\begin{array}{l}6 \\
(1) \\
\end{array}$ & $\begin{array}{l}0.02 \\
(0.01-0.04)\end{array}$ & $\begin{array}{l}0.02 \\
(0.01-0.04)\end{array}$ & $\begin{array}{l}3 \\
(1) \\
\end{array}$ & $\begin{array}{l}0.02 \\
(0-0.05)\end{array}$ & $\begin{array}{l}0.02 \\
(0-0.05) \\
\end{array}$ & $\begin{array}{l}3 \\
(0.9) \\
\end{array}$ & $\begin{array}{l}0.02 \\
(0-0.05) \\
\end{array}$ & $\begin{array}{l}0.02 \\
(0-0.05) \\
\end{array}$ & 0.912 & 0.978 \\
\hline Total & $\begin{array}{l}626 \\
(100)\end{array}$ & $\begin{array}{l}1.86 \\
(1.72-2.01)\end{array}$ & $\begin{array}{l}1.25 \\
(1.14-1.35)\end{array}$ & $\begin{array}{l}299 \\
(100)\end{array}$ & $\begin{array}{l}1.80 \\
(1.61-2.02)\end{array}$ & $\begin{array}{l}1.37 \\
(1.20-1.56)\end{array}$ & $\begin{array}{l}327 \\
(100)\end{array}$ & $\begin{array}{l}1.93 \\
(1.73-2.16)\end{array}$ & $\begin{array}{l}1.12 \\
(0.97-1.29)\end{array}$ & 0.709 & 0.040 \\
\hline
\end{tabular}

a Age-adjusted.

\section{Results}

Of a total of 626 patients with FEIS (age $71.7 \pm 13.2$ years; range 31-102 years), female patients ( $\mathrm{n}=326$; 73.5 \pm 12.6 years) were older than male patients $(\mathrm{n}=299 ; 69.7$ \pm 11.5 years; $p<0.001$ ). Crude incidence rates (per 1,000 person-years) did not show any significant sex differences. However, age-adjusted incidence rates were significantly higher in men $(1.37 ; 95 \%$ CI $1.20-1.56)$ than in women $(1.12$; 95\% CI 0.97-1.29; $\mathrm{p}=0.04)$ (table 1).

\section{Stroke Etiology}

Patients with FEIS received one or more of the following assessments: CCT ( $\mathrm{n}=569,91.0 \%$; men 91.3\%; women $90.8 \%$ ), cranial MRI ( $n=227,36.3 \%$; men $38.3 \%$; women $34.3 \%)$, extra- and transcranial vascular ultrasound ( $\mathrm{n}=567,90.6 \%$; men $91.3 \%$; women $89.9 \%$ ), transthoracic $(\mathrm{n}=474,75.7 \%$; men $75.6 \%$; women $75.8 \%)$ or transesophageal echocardiography $(\mathrm{n}=81,12.9 \%$; men $14.7 \%$; women $11.3 \%)$, ECG $(n=626,100 \%)$ and Holter monitoring $(\mathrm{n}=565,90.4 \%$; men $89.3 \%$; women $91.7 \%)$. There was no significant difference in diagnostic workup between male and female stroke patients.

Crude and age-adjusted incidence rates of subtypes of ischemic stroke are depicted in table 1. Interrater agreement for the use of modified TOAST criteria was good with a $\kappa$ value of 0.69 . Among the 626 patients with FEIS, cardioembolism was the most common etiology $(n=219$,
$35.0 \%)$, followed by small-artery occlusion ( $\mathrm{n}=164$, $26.2 \%)$ and stroke due to large-artery atherosclerosis ( $\mathrm{n}=$ 98, 15.7\%). Eighty-four patients (13.4\%) were diagnosed with 'probable atherothrombotic stroke' and 55 patients had stroke of undetermined etiology (8.8\%). Stroke due to large-artery atherosclerosis was significantly more common in men than in women in both crude and ageadjusted analyses. Cardioembolic stroke was significantly more common in men after age adjustment $(\mathrm{p}=0.022)$ but not in terms of crude rates. Cardioembolic stroke not associated with atrial fibrillation (AF) was diagnosed in 32 patients. The sources for non-AF cardioembolism where symptomatic congestive heart failure with ejection fraction of less than $30 \%(n=18)$, severe stenosis of mitral or aortic valve $(n=5)$, patent foramen ovale in combination with atrial septal aneurysm $(n=3)$, patent foramen ovale $(\mathrm{n}=2)$, left ventricular thrombus $(\mathrm{n}=2)$, infective endocarditis $(n=1)$ and left atrial myxoma $(n=1)$. The proportion of cardioembolic stroke not associated with AF was significantly higher in men $(\mathrm{n}=23,7.7 \%$ of all FEIS) than in women $(n=9,2.8 \% ; \mathrm{p}=0.004)$.

\section{Stroke Risk Factors and Stroke Survival}

Table 2 presents sex-specific risk factor profiles in ischemic stroke. Men were more often current smokers or had a history of smoking and suffered more often from CAD and PAD than women. There were no significant differences in the other risk factors. Stroke sur- 
Table 2. Risk factors in FEIS according to sex

\begin{tabular}{|c|c|c|c|c|c|c|c|}
\hline \multirow[t]{2}{*}{ Risk factor } & \multicolumn{2}{|l|}{ Total } & \multicolumn{2}{|l|}{ Men } & \multicolumn{2}{|l|}{ Women } & \multirow[t]{2}{*}{$\mathrm{p}$ value } \\
\hline & $\mathrm{N}^{\mathrm{a}}$ & $\%$ & $\mathrm{~N}^{\mathrm{a}}$ & $\%$ & $\mathrm{~N}^{\mathrm{a}}$ & $\%$ & \\
\hline Hypertension & $539 / 620$ & 86.9 & $264 / 297$ & 88.9 & $275 / 323$ & 85.1 & 0.17 \\
\hline Diabetes mellitus & $195 / 615$ & 31.7 & $87 / 291$ & 29.9 & $108 / 324$ & 33.3 & 0.36 \\
\hline $\mathrm{AF}$ & $187 / 626$ & 29.9 & $83 / 299$ & 27.8 & $104 / 327$ & 31.8 & 0.61 \\
\hline Hypercholesterolemia & $384 / 600$ & 64.0 & $174 / 287$ & 60.6 & $210 / 313$ & 67.1 & 0.10 \\
\hline Current smoking & $132 / 591$ & 22.3 & $77 / 285$ & 27.0 & $55 / 306$ & 18.0 & 0.008 \\
\hline History of smoking & $310 / 578$ & 53.6 & $202 / 280$ & 72.1 & $108 / 298$ & 36.2 & $<0.001$ \\
\hline CAD & $150 / 609$ & 24.6 & $89 / 293$ & 30.4 & $61 / 316$ & 19.3 & 0.0015 \\
\hline PAD & $58 / 606$ & 9.6 & $36 / 291$ & 12.4 & $22 / 315$ & 7.0 & 0.024 \\
\hline
\end{tabular}

${ }^{\text {a }}$ Number of observations/total number of cases.

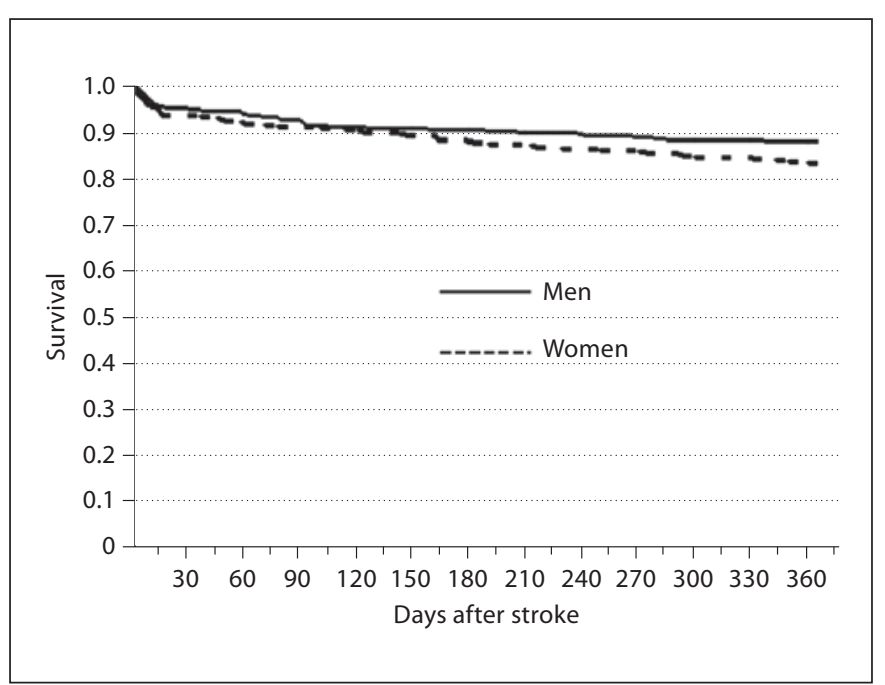

Fig. 1. Kaplan-Meier estimate of sex-specific survival after ischemic stroke.

vival was not significantly different between both sexes (fig. 1; log-rank test, $\mathrm{p}=0.92$ ). Age- and sex-specific survival rates after ischemic stroke are shown in table 3. Higher age was associated with poorer survival after ischemic stroke in both sexes ( $p<0.0001$, respectively). Cox regression analysis showed a significant interaction between age as a continuous variable and gender ( $\mathrm{p}=$ $0.025)$ towards higher mortality in older women. This is due to a high number of women $(n=28)$, but not men $(\mathrm{n}=2)$ aged 90 years and older. In contrast, no significant interaction was found if age was categorized as shown in table $3(\mathrm{p}=0.23)$.

\section{Discussion}

LuSSt is a population-based stroke registry in the industrial city of Ludwigshafen in Germany. We recently published slightly higher stroke incidence rates compared to other registries in Western and Central Europe [1]. Optimized stroke treatment and prevention has to be adapted to current and regional needs. Therefore, we analyzed etiology and sex-specific differences in ischemic stroke in LuSSt.

Compared to men women were approximately 4 years older when they suffered their first stroke. Compared to other recent studies our results are in the lower age difference range, which might be explained by relatively high incidence rates especially in women in the middleaged group [14, 15]. Crude incidence rates for FEIS showed no significant differences between the sexes. After age adjustment there was a significant male preponderance in FEIS. This effect of age adjustment is largely explained by the predominance of women in higher age groups which is seen in the population of Ludwigshafen (population $>75$ years: 4,770 men vs. 8,779 women) similar to other populations in western societies. In the past, stroke was assumed to be primarily a disease in men; however, recent data revealed the growing impact of stroke in women, which is mainly related to the rapidly growing population segment of elderly women [16-18].

We used a modification of the TOAST criteria to analyze stroke etiology. Strict application of the TOAST criteria would imply a high rate of stroke of undetermined etiology. This proportion has increased somewhat recently alongside better stroke diagnostics and a larger number of patients with more than one likely cause. In 
Table 3. Age- and sex-specific 1-year survival in ischemic stroke

\begin{tabular}{|c|c|c|c|c|c|c|}
\hline \multirow{2}{*}{$\begin{array}{l}\text { Age } \\
\text { group }\end{array}$} & \multicolumn{3}{|l|}{ Men } & \multicolumn{3}{|l|}{ Women } \\
\hline & $\mathrm{N}^{\mathrm{a}}$ & $\begin{array}{l}\text { 1-year } \\
\text { survival rate }\end{array}$ & $95 \% \mathrm{CI}$ & $\mathrm{N}^{\mathrm{a}}$ & $\begin{array}{l}\text { 1-year } \\
\text { survival rate }\end{array}$ & $95 \% \mathrm{CI}$ \\
\hline$<55$ years & $28 / 31$ & 0.90 & $0.79-0.96$ & $32 / 33$ & 0.97 & $0.89-0.99$ \\
\hline 55-64 years & $56 / 61$ & 0.92 & $0.84-0.96$ & $34 / 39$ & 0.87 & $0.76-0.94$ \\
\hline $65-74$ years & $75 / 88$ & 0.85 & $0.77-0.91$ & $78 / 85$ & 0.92 & $0.85-0.96$ \\
\hline $75-84$ years & $73 / 97$ & 0.75 & $0.67-0.83$ & $83 / 111$ & 0.75 & $0.67-0.82$ \\
\hline$>85$ years & $15 / 21$ & 0.71 & $0.53-0.85$ & $23 / 56$ & 0.41 & $0.30-0.53$ \\
\hline All age groups & $247 / 298^{b}$ & 0.83 & $0.78-0.87$ & $250 / 324^{\mathrm{b}}$ & 0.77 & $0.73-0.81$ \\
\hline
\end{tabular}

${ }^{a}$ Number of survivors/total number of cases. ${ }^{\mathrm{b}}$ Survival is unknown in 1 man and 3 women.

patients with more than one possible etiology we identified the most likely causative mechanism using the SSSTOAST system [7]. Additionally the subgroup 'probable atherothrombotic stroke' was introduced for the relatively high proportion of patients in whom nonstenotic extracranial or intracranial atherosclerotic vessel disease was found in the absence of alternative etiologies. In these patients, nonstenotic atherosclerosis may be a marker for more severe atherosclerotic disease at more distant, nonvisualized arterial segments or activated nonstenotic plaques that may have caused arterioarterial embolism. Overall, classification of stroke subtype was similar to that used in the PERFORM study [5].

We found cardioembolism to be the most common source of ischemic stroke. This is in line with recently published data [19-21]. Compared to previous studies using the TOAST classification 'stroke of undetermined etiology' was diagnosed less frequently. This may be explained by the intensive workup in our patients and mainly by modifications of TOAST criteria mentioned above. With strict application of the original TOAST criteria, the patients with 'probable atherothrombotic stroke' (13.4\%) would have been qualified as patients with stroke of undetermined etiology resulting in a rate of $22.2 \%$ in this category. Using modified TOAST criteria has been shown to reduce the percentage of patients classified as 'undetermined' [7].

Sex-specific analyses showed a higher incidence of stroke due to large-artery atherosclerosis in both crude and age-adjusted analyses in men. This result is in line with recently published study results $[2,14,22]$. Surprisingly there was no significant difference in cardioembolic stroke in our registry although a majority of studies report it to be more common in women [14, 16, 23, 24]. Age adjustment even resulted in a significantly higher incidence of cardioembolic stroke in men. Data from other registers showed comparable age-adjusted incidence rates of cardioembolic stroke in women while in men these rates were significantly lower than in Ludwigshafen [Ludwigshafen (LuSSt 2006-2007): 0.48 (95\% CI $0.38-0.59)$ in men and 0.32 (95\% CI $0.24-0.41$ ) in women; Erlangen (ESPro 1994-1998): 0.29 (95\% CI 0.21-0.38) in men and 0.31 (95\% CI 0.25-0.38) in women] [22]. Cardioembolism associated with $\mathrm{AF}$ was not different for the sexes. The proportion of cardioembolic stroke not associated with AF was significantly higher in men than in women. Enhanced diagnostic workup of stroke patients (high proportion of transthoracic and transesophageal echocardiography) may account for this result and may partly explain the intriguing finding in sex differences in cardioembolic stroke. It is important to mention that some of the criteria for cardioembolism used in the original TOAST classification (especially patent foramen ovale) are nowadays disputed [25]. However, non-AF cardioembolic stroke was only diagnosed in 2 patients with isolated patent foramen ovale. They could have also been classified as 'stroke of undetermined etiology' which would not significantly change incidence rates. Although we made every efforts to achieve almost complete case ascertainment underrepresentation of elderly women with cardioembolic stroke cannot be ruled out entirely. Cardioembolic stroke is the main source for ischemic stroke in most registers (as it is in LuSSt) and current epidemiological trends show that the impact of cardioembolic stroke will increase further in the future [26]. Hence optimizing diagnostics and stroke prevention in patients with AF might help to reduce the future burden of stroke.

Notably, there was a trend towards higher incidence of stroke of undetermined etiology in women. This trend 
was also observed in other studies [24]. In our study it was not caused by differences in diagnostic workup between male and female patients.

Data on sex-specific risk factors in ischemic stroke show conflicting results $[23,27,28]$. The higher prevalence of current smoking, history of smoking, CAD and PAD in men in our study is in line with previous studies $[14,16,24]$. Like smoking, CAD and PAD are important contributors to atherosclerotic disease, sex-specific differences in these risk factors make for differences in stroke etiology (large-artery atherosclerosis, cardioembolism not related to AF). A high prevalence of vascular risk factors overall, and of arterial hypertension in particular, highlights possible targets for prevention measures. Right now rather small sex-specific differences do not justify differences in preventive strategies.

There are conflicting results regarding stroke survival in both sexes. Recently published studies showed no sexspecific differences in stroke survival [14, 29]. In contrast, significant differences towards higher case fatality in women were shown in a recent review, pooling data from over 14,000 stroke patients [2]. Survival rates after FEIS showed no significant differences between the sexes in our study. The 1-year survival rate after ischemic stroke revealed significant differences for age by gender interaction if age was used as a continuous variable. The significance for the term age by gender disappeared after stratification into age bands, which indicates that our sample size was not large enough to compensate for the loss in statistical power after the addition of discrete parameters. This may also be the result of different age distributions especially within the higher age groups. There was a trend towards lower survival of women in higher age groups. If this finding is confirmed by larger studies, the rapidly growing segment of elderly women might lead to significant gender differences in stroke survival in the future.

\section{Conclusion}

We found cardioembolism to be the most frequent etiology of ischemic stroke. Optimizing diagnostics and stroke prevention in patients at high risk for cardioembolism (e.g. AF) might help to reduce the burden of stroke in the future. Higher incidence of cardioembolism not related to AF in men is probably explained by sex-specific differences in risk factors and requires further investigation.

Ischemic stroke etiology differs between sexes with large-artery atherosclerotic stroke and associated diseases (CAD, PAD) being more common in men. However, high prevalence of stroke risk factors overall emphasizes current needs for optimized preventive strategies.

\section{Acknowledgments}

The Ludwigshafen Stroke Registry received unrestricted funding by Boehringer Ingelheim, Sanofi-Aventis and BASF. Data analysis was supported by a grant from the Deutsche Forschungsgemeinschaft (DFG; GR1102/6-1). Study design, data collection, data analysis and data interpretation were independent from any study sponsor. LuSSt is part of the German Competence Network Stroke.

\section{Disclosure Statement}

The authors report no conflicts of interest regarding this paper.

\section{References}

1 Palm F, Urbanek C, Rose S, Buggle F, Bode B, Hennerici MG, Schmieder K, Inselmann G, Reiter R, Fleischer R, Piplack KO, Safer A, Becher H, Grau AJ: Stroke incidence and survival in Ludwigshafen am Rhein, Germany: the Ludwigshafen stroke study (LuSSt). Stroke 2010;41:1865-1870.

-2 Appelros P, Stegmayr B, Terent A: Sex differences in stroke epidemiology: a systematic review. Stroke 2009;40:1082-1090.

$\checkmark 3$ Hatano S: Experience from a multicentre stroke register: a preliminary report. Bull World Health Organ 1976;54:541-553.
4 Adams HP Jr, Bendixen BH, Kappelle LJ, Biller J, Love BB, Gordon DL, Marsh EE 3rd: Classification of subtype of acute ischemic stroke. Definitions for use in a multicenter clinical trial. Toast. Trial of Org 10172 in Acute Stroke Treatment. Stroke 1993;24:35-41.

$\checkmark 5$ Touboul PJ, Elbaz A, Koller C, Lucas C, Adrai V, Chedru F, Amarenco P: Common carotid artery intima-media thickness and brain infarction: the Etude du Profil Génétique de l'Infarctus Cérébral (GENIC) casecontrol study. The GENIC Investigators. Circulation 2000;102:313-318
6 Bousser MG, Amarenco P, Chamorro A, Fisher M, Ford I, Fox K, Hennerici MG, Mattle HP, Rothwell PM: Rationale and design of a randomized, double-blind, parallel-group study of terutroban $30 \mathrm{mg} /$ day versus aspirin $100 \mathrm{mg} /$ day in stroke patients: the prevention of cerebrovascular and cardiovascular events of ischemic origin with terutroban in patients with a history of ischemic stroke or transient ischemic attack (PERFORM) study. Cerebrovasc Dis 2009;27:509-518.

$\checkmark 7$ Ay H, Furie KL, Singhal A, Smith WS, Sorensen AG, Koroshetz WJ: An evidencebased causative classification system for acute ischemic stroke. Ann Neurol 2005;58: 688-697. 
8 The sixth report of the Joint National Committee on prevention, detection, evaluation, and treatment of high blood pressure. Arch Intern Med 1997;157:2413-2446.

$\checkmark 9$ Balkau B: The decode study. Diabetes epidemiology: collaborative analysis of diagnostic criteria in Europe. Diabetes Metab 2000;26: 282-286.

$\checkmark 10$ Bonita R, Broad JB, Anderson NE, Beaglehole R: Approaches to the problems of measuring the incidence of stroke: The Auckland Stroke Study, 1991-1992. Int J Epidemiol 1995;24:535-542.

11 Feigin VL, Carter K: Editorial comment stroke incidence studies one step closer to the elusive gold standard? Stroke 2004;35: 2045-2047.

-12 Sudlow CL, Warlow CP: Comparing stroke incidence worldwide: what makes studies comparable? Stroke 1996;27:550-558.

$\checkmark 13$ Doll R, Cook P: Summarizing indices for comparison of cancer incidence data. Int J Cancer 1967;2:269-279.

- 14 Förster A, Gass A, Kern R, Wolf ME, Ottomeyer C, Zohsel K, Hennerici M, Szabo K: Gender differences in acute ischemic stroke: etiology, stroke patterns and response to thrombolysis. Stroke 2009;40:2428-2432.

-15 Andersen KK, Andersen ZJ, Olsen TS: Ageand gender-specific prevalence of cardiovascular risk factors in 40,102 patients with first-ever ischemic stroke: a Nationwide Danish Study. Stroke 2010;41:2768-2774.

-16 Arboix A, Oliveres M, Garcia-Eroles L, Maragall C, Massons J, Targa C: Acute cerebrovascular disease in women. Eur Neurol 2001;45:199-205.
17 Mosca L, Manson JE, Sutherland SE, Langer RD, Manolio T, Barrett-Connor E: Cardiovascular disease in women: a statement for healthcare professionals from the American Heart Association. Writing Group. Circulation 1997;96:2468-2482.

18 Rosamond W, Flegal K, Furie K, Go A, Greenlund K, Haase N, Hailpern SM, Ho M, Howard V, Kissela B, Kittner S, Lloyd-Jones D, McDermott M, Meigs J, Moy C, Nichol G, O’Donnell C, Roger V, Sorlie P, Steinberger J, Thom T, Wilson M, Hong Y: Heart disease and stroke statistics - 2008 update: a report from the American Heart Association Statistics Committee and Stroke Statistics Subcommittee. Circulation 2008; 117:e25-e146.

19 Grau AJ, Weimar C, Buggle F, Heinrich A, Goertler M, Neumaier S, Glahn J, Brandt T, Hacke W, Diener HC: Risk factors, outcome, and treatment in subtypes of ischemic stroke: The German Stroke Data Bank. Stroke 2001;32:2559-2566.

20 Hannon N, Sheehan O, Kelly L, Marnane M, Merwick A, Moore A, Kyne L, Duggan J, Moroney J, McCormack PM, Daly L, Fitz-Simon N, Harris D, Horgan G, Williams EB, Furie KL, Kelly PJ: Stroke associated with atrial fibrillation - incidence and early outcomes in the north Dublin population stroke study. Cerebrovasc Dis 2010;29:43-49.

-21 Marnane M, Duggan CA, Sheehan OC, Merwick A, Hannon N, Curtin D, Harris D, Williams EB, Horgan G, Kyne L, McCormack PM, Duggan J, Moore A, Crispino-O’Connell G, Kelly PJ: Stroke subtype classification to mechanism-specific and undetermined categories by TOAST, A-S-C-O, and causative classification system: direct comparison in the North Dublin population stroke study. Stroke 2010;41:1579-1586.
22 Kolominsky-Rabas PL, Weber M, Gefeller O, Neundoerfer B, Heuschmann PU: Epidemiology of ischemic stroke subtypes according to toast criteria: incidence, recurrence, and long-term survival in ischemic stroke subtypes: a population-based study. Stroke 2001; 32:2735-2740.

$\checkmark 23$ Holroyd-Leduc JM, Kapral MK, Austin PC, Tu JV: Sex differences and similarities in the management and outcome of stroke patients. Stroke 2000;31:1833-1837.

24 Roquer J, Campello AR, Gomis M: Sex differences in first-ever acute stroke. Stroke 2003;34:1581-1585.

25 Amarenco P: Underlying pathology of stroke of unknown cause (cryptogenic stroke). Cerebrovasc Dis 2009;27(suppl 1):97-103.

26 Arboix A, Cendros V, Besa M, Garcia-Eroles L, Oliveres M, Targa C, Balcells M, Comes E, Massons J: Trends in risk factors, stroke subtypes and outcome. Nineteen-year data from the Sagrat Cor Hospital of Barcelona stroke registry. Cerebrovasc Dis 2008;26:509-516.

27 Petty GW, Brown RD Jr, Whisnant JP, Sicks JD, O'Fallon WM, Wiebers DO: Ischemic stroke subtypes: a population-based study of incidence and risk factors. Stroke 1999;30: 2513-2516.

28 Sharma JC, Fletcher S, Vassallo M: Characteristics and mortality of acute stroke patients: are there any gender differences? J Gend Specif Med 2002;5:24-27.

29 Petrea RE, Beiser AS, Seshadri S, KellyHayes M, Kase CS, Wolf PA: Gender differences in stroke incidence and poststroke disability in the Framingham heart study. Stroke 2009;40:1032-1037. 